
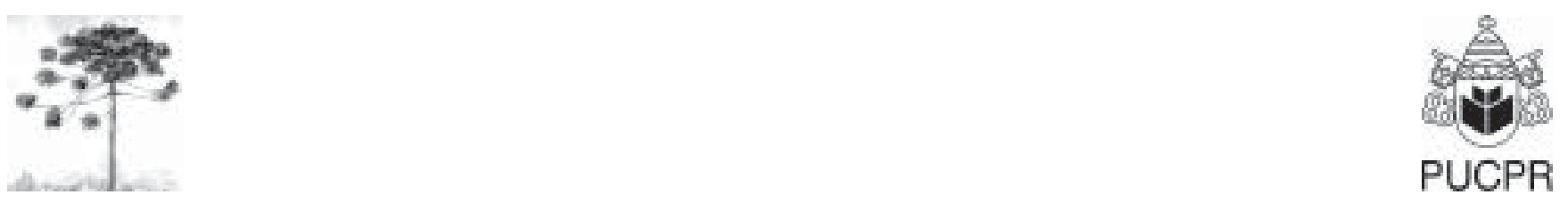

\title{
EVALUATION OF POWDER PROPERTIES FROM THE SEED COAT OF TINGUI (Magonia pubesoend) AS AN EXCIPIENT FOR SEED PELLETING
}

\author{
A valiação das propriedades das partículas do envoltório da semente do Tingui \\ (Magonia pubescens) como um ingrediente para a peletização de sementes
}

\author{
Antonio Zenon Antunes T eixeira
}

Chemistry D epartment - Federal University of Mato G rosso - UFMT, Cuiabá, MT - Brazil, e-mail: azteixei@ ufmt.br

\begin{abstract}
The aim of this study was to investigate the physical properties of the seed coat of Tingui (M agonia pubescens) in order to evaluate the performance of this polysaccharide as an excipient for seed pelleting. The analysis was emphasized to the flow properties including particle size, particle size distribution, density and moisture content of the substance. The results were compared to commercial excipients including Microcrystalline cellulose (MCC PH 101 and SMCC), Hydroxypropyl methylcellulose (HPMC E 50), Polyvinil pirrolidone (PV P K 29/ 32), lactose and corn starch. The data showed that Tingui was found to have bulk and tap density close to HPMC and corn starch. Particle size and its distribution were fit to HPMC and PVP; however, Tingui had moisture content quite close to SMCC and HPMC. In general, Tingui exhibited the free-flow properties comparable to HPMC and PVP. E nergy dispersive X-ray fluorescence analysis confirmed that the seed coat of Tingui contains elements (K, Ca, Si and Fe) composition.
\end{abstract}

Keywords: Tingui; M agonia Pubesœens; Seed pelleting; Seed coating; Seed binder; Hydrogel.

\section{Resumo}

O principal propósito desse estudo foi investigar as propriedades físicas do envoltório da semente do Tingui (Magonia pubescens) com objetivo de avaliar a utilidade desse polissacarídeo como um ingrediente para a peletização de sementes. As análises enfatizaram as propriedades de fluidez incluindo tamanho das partículas, distribuição das partículas por tamanho, densidade e a umidade das substâncias. Os resultados foram comparados com os ingredientes comerciais celulose microcristalina (MCC PH 101 e SMCC), hidroxipropil metilcelulose (HPMC E50), polivinil pirrolidona (PVP K29/32), lactose e amido de milho. 
Os dados mostram que Tingui possui densidade de volume e de compactação semelhantes ao HPMC e amido de milho. Tamanho das partículas e sua distribuição se adequam ao HPMC e PVP, entretanto, Tingui possui uma quantidade de humidade próximo ao SMCC e HPMC. Em geral, Tingui, apresenta propriedades de fluidez livre comparável ao HPMC e PVP. Análises de fluorescência de raio-x por energia de dispersão do Tingui mostrou que o envoltório da semente de Tingui contém em sua composição (K, Ca, Si e Fe).

Palavras-chave: Tingui; Magonia pubescens; Seed pelleting; Seed coating; Seed binder; Hydrogel.

\section{INTRODUCTION}

The use of treated vegetable seeds has increased dramatically during a decade. Many growers now use more expensive hybrid seeds to improve performance in the field to protect their investment. Fungicide applications are one of the more common seed treatments used today that is usually applied to the seeds coat. Today, coating and pelleting are two widely used in seed treatment, principally with small-seeded species. This makes seeds easier to handle $(1,2)$ and plant particularly with seeders that utilize belts with prepunched holes of a specific size.

There are two components of a seed pelleting: bulking (coating) material and binder. The old process was done by using a mixture of sand and microcellulose (2). Today, the bulking material can be either a mixture of several different minerals and/ or organic substances. The coating material alters the size, shape and weight of the seed. D esirable characteristics of a good coating material include: uniformity of particle size distribution, availability of material, and lack of phytotoxicity. Seed coating relies on technology developed by the pharmaceutical industry to produce solid dosage forms. The formulations are typically combined with additional polymers, filler and pigment. Polymers have been used in a variety of agricultural applications, such as preserving seed germinability and chelating fertilizer release $(3,4)$. The coating delay the movement of the water from the soil to the seed by absorbing water into its polymer structure (5), thus the precision formulation may regulate the seed germination. For example, the polymer Extender ${ }^{\circledR}$ (Grow Tec Seed Coating, Inc.) has been developed to prevent seed from imbibing water until soil temperatures begin to warm in late winter-early spring. The second component, the binder, holds the coating material together. Binder concentration is critical because too much binder will delay germination. Too little binder will cause chipping and cracking of pellets in the planter box, which can cause skips and/ or wide gaps in the plant rows. Many different compounds have been used as binders, including various starches, sugars, gum arabic, clay, cellulose, vinyl polymers (6) and even water (7).

Magonia pubescens is known locally in Brazil as Tingui. The trees grow in the savanna regions, most commonly in west and central parts of Brazil. The seed has flat elliptical shape. The external coat of the seed has five regions. O $\mathrm{n}$ wetting, the second one, defined as starting from the outer region, forms a hydrogel when immersed in water (8) that may be important for adaptation to extended drought in terms of germination (9) and to help the seeds adhere to the soil surface (10). In addition to being a germination promoter, it has antifungal properties against Penicillium, A spergillus, and $\mathrm{H}$ ormodendrum spp. However, this antifungal activity appears to be inhibited when the gel is exposed to high temperatures (8). The hydrogel from M. pubescens consists mainly of carbohydrates. Analysis using CP-MAS ${ }^{13} \mathrm{C}$ NMR spectrum produced signals at ä 176.8 ( $\mathrm{C}=0$ of uronic acid and acetate), 104.7 (C1; â-xylopyranose, â-glucopyranose), 98.5 [C-1, áglucopyranose (uronic acid)], 63.8 (C-5; âxylopyranose), $21.0\left(\mathrm{CH}_{3}\right.$, acetate), and 17.3 (C-6, á-rhamnopyranose), corresponding to the hydrogel (11). Fahn (1990) reported that mucilages are common in many seeds, and they may either contain no cellulose or cellulose microfibrils. In relation to the second layer components, the Tingui gel consists mainly of cellulosic compounds and acidic hemicellulosic polysaccharides, an example of the second type of mucilaginous material cited above (12). According to Fahn (1990), the extrusion 
phenomenon of mucilaginous compounds is related to seed dispersion. They may regulate germination, by preventing dehydration or, in the case of excess water; the mucilage may envelop the seed, avoiding germination due to deficiency of oxygen.

Since Tingui polysaccharides has gel and antifungal properties, it can be proposed as an excipient of seed coating or binder. One of the most important requirements for compressible filler binder is good flowability of the powder (13). It is typically determined by powder properties such as particle size, particle size distribution, density and moisture content (14). A good flowability is critical to guarantee rapid and uniform die filling during pellet formation. The purpose of this work is to evaluate the physical properties of the seed coat from Tingui (M agonia pubescens) as an excipient compared with commercial excipients, Polyvinylpyrrolidone (PVP), Hydroxypropyl methylcellulose (HPMC), Microcrystaline cellulose (MCC), lactose and Starch). PVP (trade name Agrimer ${ }^{\circledR}$, International Specialty Product, Wayne, $\mathrm{NJ}$ ) and HPMC have been used in wettable powder formulation on a wide variety of seeds. In addition, the Tingui sample was also examined for its elemental composition.

\section{MATERIAL AND METHODS}

\section{MATERIALS}

All materials except Tingui were complied with current USP/NF compendial specifications and all were obtained from T oronto Institute Pharmaceutical Technology (TIPT), ON, Canada. Polyvinylpyrrolidone (PVP K29/ 32) (lot \# TX 70913), Microcrystalline cellulose (MCC PH 101) (lot \# 04B0204), Silicified Microcrystalline cellulose (SMCC) (lot \# 04B0107), Hydroxypropyl Methylcellulose (HPMC E50) lot \# T98B904, Lactose Monohydrate (lot \# 04B0204), Corn Starch (lot \# T97B307). Tingui seeds were collected in the campus of the Federal University of Mato G rosso, Cuiaba, Brazil. The external coat of the seeds was manually isolated from the rest of the seed with the aid of a razor blade and the powder was blended using Mill Pulverizing System AMEF for physical analysis.

\section{METHODS}

\section{Density and carr's index}

In determining bulk density, bulk powder was transferred carefully to a $100 \mathrm{~mL}$ cylinder using a scoopula and the volume was recorded. This procedure was performed three times and calculated the average of weight of the powder divided by the volume of powder. To measure tapped density, the cylinder was tapped 100 times, continued until a constant volume was obtained, and recorded the volume. This procedure was performed three times and calculated its average by formula: weight of powder / volume of powder. Carr's index was measured using formula [(tapped density-bulk density)/ tapped density] x 100\%.

The true or absolute densities were carried out using a pycnometer with a known volume and accurately weighed. The pycnometer was filled with immersion fluid hexane at $25^{\circ} \mathrm{C}$ which samples can not be soluble.

The true density was calculated by the following formula:

$$
\text { True density }(15)=\frac{C}{\bar{B}-\bar{E}-(\bar{C}-\bar{A})}
$$

Where:

$$
\begin{aligned}
& A=\text { weight in grams of pycnometer. } \\
& B=\text { volume of pycnometer in milliliters. } \\
& C=\text { weight of dry sample. } \\
& D=\text { density of the solvent at } 25^{\circ} \mathrm{C} \text {. } \\
& E=\text { total weight in grams of the } \\
& \text { pycnometer containing the solvent and } \\
& \text { the sample at } 25^{\circ} \mathrm{C} \text {. }
\end{aligned}
$$

\section{Moisture content}

The moisture content of the excipients was measured gravimetrically on Sartorius Moisture Balance. Approximately $3 \mathrm{~g}$ of sample was uniformly placed onto the sample pan, and then the heating cycle was started. The percentage of moisture content was determined from the weight loss of the sample by heating. The total 
moisture content from the powders were measured by Karl Fischer titration based on the reaction of $\mathrm{H}_{2} \mathrm{O}$ with an amine, $\mathrm{I}_{2}, \mathrm{SO}_{2}$, and an alcohol.

\section{Angle of repose}

The angle of repose was determined from the dimensions of the powder pile. The powder is passed through a funnel which is lifted to allow the material to form a powder heap. The shape of the powder heap used to determine how well the powder flow. The formula used is tan á $=2$ height $/$ diameter (15).

\section{Particle size and its distribution}

Particle size and its distribution were analyzed using a shaker machine, ROTAP model
RX 29. The procedures for the sieve analysis followed the USP Physical Tests $<786>$ on solid particles. The screens were weighed individually prior to operation of the machine. A $100 \mathrm{~g}$ of sample was shaken for 5 minutes on the standard sieves. Each of the sieves along with the retained particles was weighed individually after shaking. The conversion of mesh size into micron is based on the U.S. standard scale.

\section{Fluorescence}

The sample of Tingui $(2.4 \mathrm{~g})$ was carried out using the pellet method $(16,17)$. The pellet are analyzed by Energy dispersive X-ray fluorescence (EDX) spectrometry using Shimadzu ED X 700HS, Lamuta laboratory, UFMT.

\section{RESULTS AND DISCUSSION}

TABLE 1 - D ensity and moisture content of materials studied

\begin{tabular}{llclll}
\hline & Bulk & $\begin{array}{c}\text { Density (g/ mL) } \\
\text { Tap }\end{array}$ & True & $\begin{array}{l}\text { Moisture } \\
\text { Content (\%) }\end{array}$ & $\begin{array}{l}\text { Karl Fischer } \\
\text { (\%) }\end{array}$ \\
\hline MCC PH 101 & $0.63 \pm 0.04$ & $0.82 \pm 0.10$ & $1.48 \pm 0.06$ & $4.60 \pm 0.18$ & $5.30 \pm 0.05$ \\
SMCC & $0.33 \pm 0.01$ & $0.43 \pm 0.01$ & $1.53 \pm 0.02$ & $2.64 \pm 0.06$ & $3.12 \pm 0.16$ \\
HPMC E50 & $0.55 \pm 0.01$ & $0.69 \pm 0.01$ & $1.26 \pm 0.00$ & $2.47 \pm 0.03$ & $3.15 \pm 0.04$ \\
Lactose & $0.61 \pm 0.03$ & $0.78 \pm 0.08$ & $1.52 \pm 0.01$ & $3.11 \pm 0.09$ & $4.10 \pm 0.09$ \\
Monohydrate & & & & & \\
Corn Starch & $0.57 \pm 0.01$ & $0.71 \pm 0.00$ & $1.35 \pm 0.02$ & $9.99 \pm 0.17$ & $11.26 \pm 0.10$ \\
PVP K29/ 32 & $0.35 \pm 0.00$ & $0.43 \pm 0.00$ & $0.90 \pm 0.01$ & $4.50 \pm 0.54$ & $5.97 \pm 0.14$ \\
Tingui & $0.48 \pm 0.01$ & $0.71 \pm 0.02$ & $1.38 \pm 0.02$ & $2.90 \pm 0.09$ & $3.18 \pm 0.05$ \\
\hline
\end{tabular}

TABLE 2 - Carr's index and angle of repose of materials studied

\begin{tabular}{llllll}
\hline & $\begin{array}{l}\text { Carr's } \\
\text { Index (\%) }\end{array}$ & $\begin{array}{l}\text { Angle of } \\
\text { Repose }\end{array}$ & & $\begin{array}{l}\text { Carr's } \\
\text { Index (\%) }\end{array}$ & $\begin{array}{l}\text { Angle of } \\
\text { Repose }\end{array}$ \\
\hline MCC PH 101 & 22.92 & $22.08^{\circ}$ & Corn Starch & 27.00 & $34.72^{\circ}$ \\
SMCC & 23.36 & $23.15^{\circ}$ & PVP K 29/ 32 & 20.00 & N/A \\
HPMC E50 & 20.63 & $35.47^{\circ}$ & Tingui & 19.40 & $34.56^{\circ}$ \\
Lactose & 21.60 & $31.23^{\circ}$ & & & \\
\hline
\end{tabular}

\section{Density}

Table 1 listed the results of bulk, tap and true density. MCC PH 1 has the highest bulk and tap densities followed by lactose, corn starch,
HPMC, SMCC and PVP. Because the excipients are primarily organics materials, their true densities did not vary significantly for most part, with most materials exhibiting values that fell within the range $1.2-1.6 \mathrm{~g} / \mathrm{mL}$ (18), with 
the exception of PVP (Table 1). Comparing to these commercial powders, Tingui was found to have bulk and tap density quite close to HPMC and corn starch.

\section{Moisture content}

The moisture content for the samples is shown in Table 1. Corn starch produced the highest moisture content followed by PVP, MCC $\mathrm{PH}$ 101, lactose, and HPMC. Tingui had moisture content similar to SMCC and HPMC.

\section{Carr's index}

Carr's index represents the degree of compressibility that can be correlated to flow, the greater the degree of compressibility, the poorer the flow. Table 2 showed that Carr's index of Tingui is fair and at the same index with HPMC and lactose.

\section{Angle of repose}

The values of angle of repose presented in Table 2 fell within the range $22^{\circ}-35^{\circ}$. Tingui had a similar angle with lactose and corn starch. Low angle of repose indicates less cohesive powder and the more free-flowing (19).

\section{Particle size}

Particle size and its distribution are shown in Figure 1. All bulk materials consist of polydispersed particle distribution with exception of com starch. Particle size of MCC PH 101, SMCC and corn starch is $<75-100 \mu \mathrm{m}$. The particle size of Tingui was similar with lactose and HPMC E50 and PVP (75 - $250 \mu \mathrm{m})$. PVP confirmed good flow with the size $100-420 \mu \mathrm{m}$.

\section{Fluorescence}

Energy dispersive X-ray fluorescence (EDX) spectrometry results confirmed that Tingui seed coat contains potassium (80 \%), followed by calcium, silicon, iron and other elements (Table 3).

TABLE 3 - X-ray fluorescence results for Tingui

\begin{tabular}{lcll}
\hline Analyte & Result (\%) & Analyte & Result (\%) \\
\hline $\mathrm{K}_{2} \mathrm{O}$ & $80.25 \pm 0.1$ & $\mathrm{P}_{2} \mathrm{O}_{5}$ & $0.36 \pm 0.14$ \\
$\mathrm{CaO}$ & $8.84 \pm 0.21$ & $\mathrm{CuO}$ & $0.32 \pm 0.13$ \\
$\mathrm{SiO}$ & $4.95 \pm 0.03$ & $\mathrm{MnO}$ & $0.25 \pm 0.02$ \\
$\mathrm{Fe}_{2} \mathrm{O}_{3}$ & $4.13 \pm 0.03$ & $\mathrm{Rb}_{2} \mathrm{O}$ & $0.22 \pm 0.01$ \\
$\mathrm{SO}_{3}$ & $0.68 \pm 0.11$ & & \\
\hline
\end{tabular}
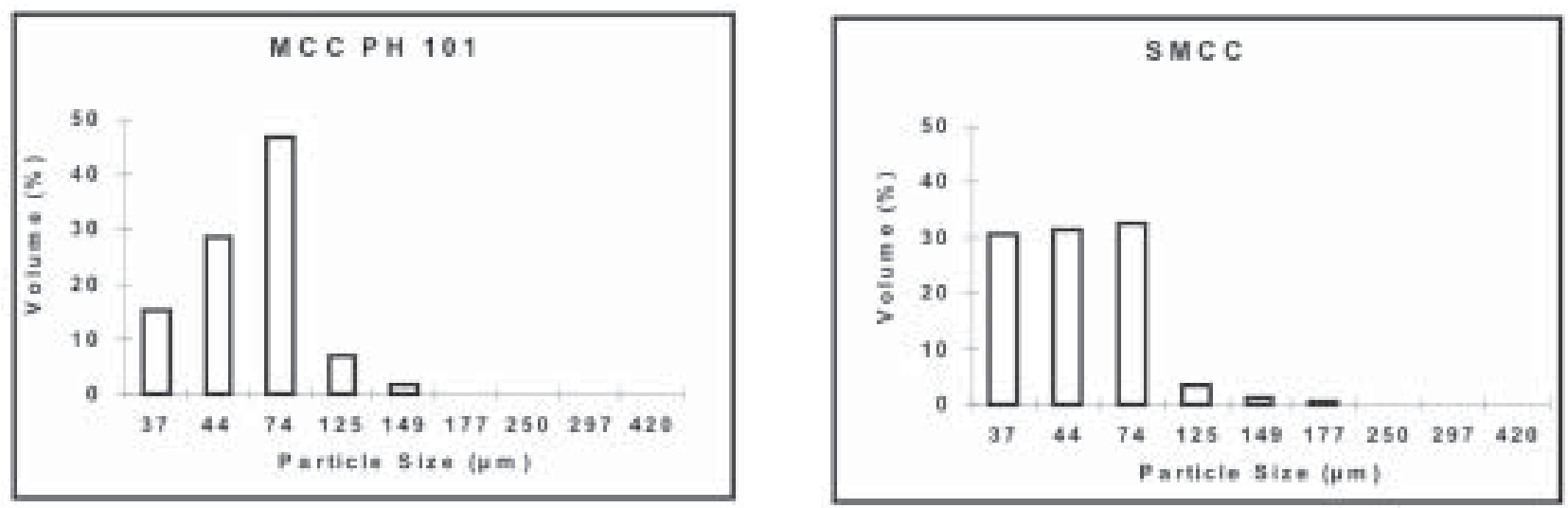

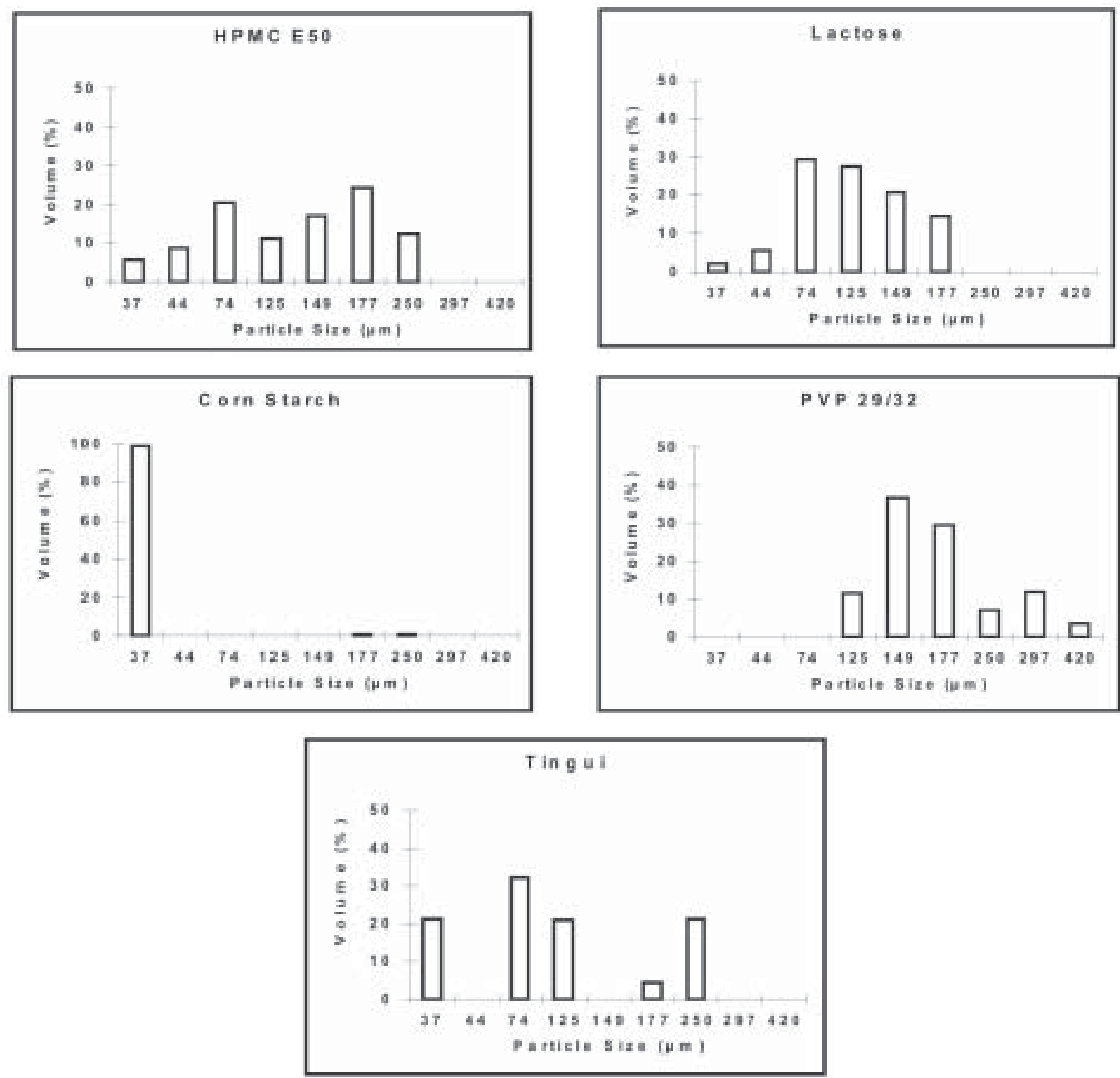

FIGURE 1 - Particle size and its distribution

\section{Flow characteristics}

Powder flow characteristics were examined based on Carr's index and angle of repose. Carr's index is determined by particle size and its distribution. Index greater than 20-25\% are classified as non-free-flowing (20). HPMC and PVP showed a lower Carr's index, it proves them to have better flow property among excipients, followed by lactose, MCC and corn starch. According to Carr (15), flow is usually good when mass of individual particles is relatively large (200 - $250 \mu \mathrm{m}$ ), were found on PVP and HPMC. On contrary, smaller particle $(<100 \mu \mathrm{m})$ may cause the flow become a problem with most substances (MCC and corn starch). Tingui formed moderate particle size $(75-250 \mu \mathrm{m})$ as well as lactose which supported their free-flowing properties. Widely distributed the size of particles may also affect how well the powder mixes or flows. As observed, larger distribution of HPMC particle contributed higher Carr's index comparing to PVP and Tingui.

Another attributes that determine the value of Carr's index are density and moisture content. MCC PH 101 showed better flow property than SMCC because of higher tap and bulk density. 
Although com starch has higher density comparing to HPMC, SMCC, PVP and Tingui, thehigh moisture content attributed to poor-flow. The bulk density does not reflect to the true density of the substance since the volumeincludes spaces between individual particles. Because the true density was evaluated of the mass particle without any void spaces between the particles, the high value on bulk and tap do not guarantee the high value on true density. Though the bulk and tap density of MCC PH 101 is higher than SMCC (Table 1), the true density showed the contradiction. The difference could be caused by the differences of particle size and the packing arrangement of the particles.

The values of angle of repose presented in Table 2 indicated that all studied powders showed good flow properties (in the range $22^{\circ}-35^{\circ}$ ). The value of angle repose will be high if the powder is cohesive that mainly correlated to the particle size. Smaller particles tend to stick together. Thus, when measuring theangle of repose, small particles (usually less than 75-100 im) are able to form a more dense packing therefore increases the angle as shown in corn starch. Large particle tend to push other particles, therefore it occurs more often lower angle of repose. Somecontradiction on theresults between Carr's index and angle of repose may arise from the inaccurate determination of powder pile.

Additionally, according to the Energy dispersive X-ray fluorescence analysis (Table 3), the seed coat of Tingui contained high concentration of potassium thatcould beuseful forfertilizerapplication. On soils marginal to deficient in $\mathrm{K}$ including organic soils that are also frequently low $\mathrm{K}$ level, high use crops will require higher rates of $\mathrm{K}$ fertilizer to maintain adequate nutrition and to improve disease resistance. Since Tingui contained high $\mathrm{K}$ concentration, an interaction of a positively charged $\mathrm{K}$ with water may maintain the formation of hydrogel that is important in increasing drought resistance.

\section{CONCLUSION}

The comparative method of studying the powder properties of the seed coat of Tingui to the commercial excipients confirmed the possibility of Tingui to be an excipient for seed pelleting. The results showed that Tingui has properties comparable to HPMC and PVP, two polymers that have been widely utilized in seed coating. The $\mathrm{K}$ content and anti fungal properties of Tingui may also improve its investment value as a material of seed pelleting. However, it must be emphasized that complete analysis of pellet properties such as hardness and plasticity behavior should be included.

\section{ACKN OWLEDGEMENT}

The author thanks Mr. Benedito Rodrigues da Silva Ferraz staff from UFMT for collecting the seeds of Tingui and Toronto InstitutePharmaceutical Technology - TIPT for powder physical analysis.

\section{REFERENCES}

1. Franzin SM, Menezes NL, Garcia DC, Roversi T. Avaliação do vigor de sementes de alface nuas e peletizadas. Revista Brasileira de Sementes. 2004;26(2):114-8.

2. Silva JBC, Santos PEC, Nascimento WM. D esempenho de sementes peletizadas de alface em função do material cimentante e da temperature de secagem dos péletes. Horticultura Brasileira. 2000;20(1):67-70.

3. Zhang $M$, Nyborg $M$, Solberg ED. Seed germination and seeding dry matter production of canola, barley and wheat as affected by seed-placed KCL and polymercoated KCL. Can J Soil Sci. 1998;78:611-4.

4. Chachalis D and Smith ML. Hydrophobicpolymer application reduces imbibition rate and partially improves germination or emergence of soybean seedlings. Seed Sci Technol. 2001;29:91-8.

5. Johnson EM, Miller PR, Blackshaw RE, G an Y, Harker KN, Clayton GW, et al. Seeding date and polymer seed coating effects on plant establishment and yield of fall-seeded canola in Northern G reat Plains. Can J Plant Sci. 2004;84:955-63.

6. Halmer P. Technical and commercial aspects of seed pelleting and film coating. Thorton Heath: British Protection Council; 1987. p. 191-204.

7. Burgesser FW. Important developments in coated seeds may save time and money. The Fruit and Vegetable Review. 1949;11:18-19. 
8. Labouriau MLS. A semente de Magonia pubescens St. Hil: morfologia e germinação. Academia Brasileira de Ciências. 1973;45:501-36.

9. Joly CA, Felippe GM, Dietrich SM, CamposTakaki GM. Physiology of germination and seed gel analysis in two populations of Magonia pubescens St. Hil. Revista Brasileira de Botânica. 1980;3:1-9.

10.Fahn A. Plant anatomy. $4^{\text {th }}$ ed. London, UK: Pergamon Press; 1990. p. 522-525.

11. Gorin PAJ, Teixeira AZA, Travassos LR, Labouriau MLS, Iacomini M. Characterization of carbohydrate components of an unusual hydrogel formed by seed coats of Magonia pubescens (Tingui). Carbohy Res. 1996;282:325-33.

12. O liveira CMR, Iacomini M, Alquini Y, G orin PAJ. Microscopic and NMR analysis of the external coat from seeds of Magonia pubescens. New Phytologist. 2001;152(3):501-9.

13. Maarschalk KVV, Bolhuis GK. Improving properties of materials for direct compaction Part I. Pharm Tech Eur. 1998;10(9):30-3.

14.Zhang Y, Law Y, Chakrabarti S. Physical properties and compact analysis of commonly used direct compression binders. AAPS PharmSciTech. 2003;4(4):E 62.
15.Lantz RJ, Schwartz JB. Mixing. In: D ekker M, Lieberman HA, Lachman L, Schwartz JB. editores. Pharmaceutical dosage forms: tablets. $2^{\text {nd }}$ ed. New York: Marcel Dekker; 1990. p. 1-71. v. 2.

16. Feret F, Jenkins R. A practical guide for the preparation of specimens for $\mathrm{x}$-ray fluorescence and $\mathrm{x}$-ray diffraction analysis. New York: Wiley; 1998.

17.Kyotani T, Iwatsuki M. Multi-element analysis of environmental samples by $\mathrm{x}$-ray fluorescence spectrometry using a simple thin-layer sample preparation technique. Analyst. 1998;123:1813-6.

18. Kibbe AH. Handbook of pharmaceutical excipients. Washington: American Pharmaceutical Association; 2000.

19. Wouters IMF, G eldart D. Characterizing semicohesive powders using angle of repose. Part Syst Charact. 1996;13:254-9.

20. Carr RL. Evaluating flow properties of solids. Chem Eng. 1965;72(2):163-9.

Received: 01/ 15/ 2007

Recebido: 15/ 01/ 2007

Approved: 02/ 22/ 2007

A provado: 22/ 02/ 2007 